\title{
Publicly Reported Wound Healing Rates: The Fantasy and the Reality
}

\author{
Caroline E. Fife, ${ }^{1,2 *}$ Kristen A. Eckert, ${ }^{3}$ and Marissa J. Carter ${ }^{3}$ \\ ${ }^{1}$ Department of Geriatrics, Baylor College of Medicine, Houston, Texas. \\ ${ }^{2}$ The U.S. Wound Registry, The Woodlands, Texas. \\ ${ }^{3}$ Strategic Solutions, Inc., Cody, Wyoming.
}

Significance: We compare real-world data from the U.S. Wound Registry (USWR) with randomized controlled trials and publicly reported wound outcomes and develop criteria for honest reporting of wound outcomes, a requirement of the new Quality Payment Program (QPP).

Recent Advances: Because no method has existed by which wounds could be stratified according to their likelihood of healing among real-world patients, practitioners have reported fantastically high healing rates. The USWR has developed several risk-stratified wound healing quality measures for diabetic foot ulcers (DFUs) and venous leg ulcers (VLUs) as part of its Qualified Clinical Data Registry (QCDR). This allows practitioners to report DFU and VLU healing rates in comparison to the likelihood of whether the wound would have healed.

Critical Issues: Under the new QPP, practitioners must report at least one practice-relevant outcome measure, and it must be risk adjusted so that clinicians caring for the sickest patients do not appear to have worse outcomes than their peers. The Wound Healing Index is a validated risk-stratification method that can predict whether a DFU or VLU will heal, leveling the playing field for outcome reporting and removing the need to artificially inflate healing rates. Wound care practitioners can report the USWR DFU and VLU risk-stratified outcome measure to satisfy the quality reporting requirements of the QPP.

Future Directions: Per the requirements of the QPP, the USWR will begin publicly reporting of risk-stratified healing rates once quality measure data have met the reporting standards of the Centers for Medicare and Medicaid Services. Some basic rules for data censoring are proposed for public reporting of healing rates, and others are needed, which should be decided by consensus among the wound care community.

Keywords: wound healing rates, Merit-Based Incentive Payment, quality measures, real world data, qualified clinical data registry, randomized controlled trials

\section{SCOPE AND SIGNIFICANCE}

WE COMPARE REAL-WORLD healing rates from the U.S. Wound Registry (USWR), a Qualified Clinical Data Registry (QCDR), with randomized controlled trials (RCTs) and publicly reported data and develop criteria for honest reporting of wound outcomes. RCT and USWR data provide convincing evidence that most wounds do not heal, whereas healing rates posted online by provider entities are so high

(C) Caroline E. Fife, Kristen A. Eckert, and Marissa J. Carter 2018; Published by Mary Ann Liebert, Inc. This is an Open Access article distributed under the terms of the Creative Commons Attribution License (http://creativecommons.org/licenses/by/4.0), which permits unrestricted use, distribution, and reproduction in any medium, provided the original work is properly cited.

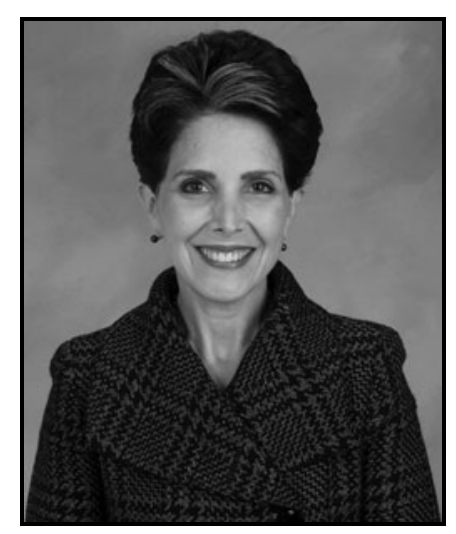

Caroline E. Fife, MD

Submitted for publication May 9, 2017. Accepted in revised form August 16, 2017.

*Correspondence: The U.S. Wound Registry, 2700 Research Forest Drive, Suite 100, The Woodlands, TX 77381

(e-mail: cfife@uswoundregistry.com). 
and cover such short time frames that they appear impossible. Although some data censoring is necessary, wounds must be risk adjusted to satisfy the quality reporting requirements of the new Quality Payment Program (QPP).

\section{TRANSLATIONAL RELEVANCE}

Under the Merit-Based Incentive Payment System (MIPS), practitioners must report at least one practice-relevant outcome measure to qualify for a bonus payment. Unfortunately, the Centers of Medicare and Medicaid Services (CMS) does not have wound care-relevant measures available. Although some data censoring is necessary, if quality data are reported by any QCDR, at least one risk-adjusted outcome measure must be reported to satisfy reporting requirements. As a solution to this conundrum, the USWR provides wound care-relevant quality measures, including risk-stratified healing rate measures for DFUs and venous leg ulcers (VLUs).

\section{CLINICAL RELEVANCE}

Without a standardized risk stratification method, there is considerable pressure to inflate publicly reported healing rates, because not to do so will make the practitioners appear less clinically capable. Based on USWR and RCT data, it is likely that in the real world, among complicated patients, healing rates better than $40.0 \%$ are not achievable. By reporting that nearly all wounds heal, we are unable to elucidate the relative contribution of specific interventions. Inflating healing rates makes it nearly impossible to develop episodebased payment models, a task upon which the future survival of the field of wound care may depend.

\section{OVERVIEW}

\section{Public reporting: the fantasy of quality data}

In 2016, the performance data of all practitioners participating in the Physician Quality Reporting System (PQRS) became publicly available for the first time on the Physician Compare website, although the data available lag 2 years behind the calendar year. ${ }^{1} \mathrm{CMS}$ is continuing its transition to a healthcare payment system based on quality rather than quantity through the MIPS, to which the vast majority of physicians became subject on January 1, 2017. ${ }^{2}$ Under the MIPS, quality reporting comprises $60 \%$ of the total performance score this first year. Practitioners hoping to realize a bonus payment must successfully report six quality measures, at least one of which should be a practice-relevant outcome measure. Since there are no wound care-relevant outcome measures available from CMS, wound care practitioners find themselves like Lewis Carroll's Alice down the rabbit hole, wondering which way to go from here. In this "through the looking glass" conundrum, MIPS success is largely dependent on the reporting of quality measures which CMS specifically did not create for wound care providers. Happily, wound care-relevant quality measures are available through the USWR, a QCDR recognized by CMS for quality measure development and reporting under MIPS. ${ }^{3,4}$ By federal law, if quality data are reported by any QCDR, at least one outcome measure must be reported and must be risk adjusted [see 78 FR 43363, Section 601(b) of the American Taxpayer Relief Act of 2012]..$^{5}$ Risk adjustment is a corrective tool to "level the playing field" when reporting patient outcomes, making it possible to compare provider performance fairly. ${ }^{6}$ In other words, if the USWR reports "healing rates" (a logical outcome measure for wounds), it must do so using a risk stratification tool to prevent practitioners caring for the sickest patients from being penalized by appearing to have poorer outcomes than their peers. With quality performance data now public on Physician Compare, ${ }^{7}$ we share Ali$c e$ 's concern that words cannot simply be allowed to mean whatever anyone choses. Payers already use quality measure performance to negotiate contracted reimbursement rates, and potential employers may use quality measure data in their hiring decisions. The online platform for crowdsourced reviews, "Yelp," which already offers physician ratings by consumers, is negotiating with CMS to integrate $\mathrm{PQRS}$ performance data from Physician Compare, transforming Yelp into the driving force of consumer decision making for healthcare providers. ${ }^{8}$ The USWR has developed two risk-stratified healing rate measures, one for diabetic foot ulcers (DFUs) and the other for VLUs. Given the farreaching implications of publicly reported outcome data and the federal mandates for risk adjustment of QCDR outcome measures, the time has come, as the Walrus said, "to talk of many things." At the very least, dialogue is needed regarding the industry norms for data censoring of wound outcomes and a change in the public reporting of wound healing rates, which are currently works of fiction.

In this review, we demonstrate how data from RCTs provide convincing evidence that most patients do not heal their wounds, despite the exclusion of most serious comorbid diseases. In contrast, the healing rates posted online by various provider entities tout wound healing rates so high and over such short time frames that they can safely be 
classified, to paraphrase Alice, among the impossible things one cannot believe. The purpose of this article is to compare real-world healing rates from the USWR with RCTs and publicly reported data, and develop a reasonable strategy for honest reporting of wound outcomes, a CMS requirement under the new Quality Payment Program.

\section{Publicly reported quality data: believing in six impossible things before breakfast}

In January 2017, we searched "wound clinic healing rates" on Google to determine publicly reported quality data by providers, hospitals, corporations, and other wound care-related businesses. The search resulted in "around 465,000 websites," of which the first 490 were provided. None of these results comprised data from clinical trials, manufacturers of devices or drugs, or any other entity not associated with the actual delivery of care as performed by an advanced practitioner in the clinical setting. We reviewed each wound center website and included publicly reported data from the first center listed with data available from each state. To determine public data transparency, we specifically searched for and collected data that targeted various consumers of healthcare (e.g., patients, hospitals, and private payers), including the following:

- the number of providers at each center

- whether there were data available for each provider

- the number of patients reported

- the number of all wounds reported

- the mean wound healing rate (\%) for all wounds

- time-to-heal (weeks) for all wounds

- the number of all DFUs reported

- the mean wound healing rate (\%) for DFUs

- time-to-heal (weeks) for DFUs

- the severity of DFUs

- whether or not adverse events were reported (including amputations, infections, and hospitalizations)

- whether or not data censoring rules were reported

- whether or not risk stratification was used.

We also checked the corresponding Facebook pages of each clinic for posts related to wound healing data. Because Google truncates the search items, we did not find a representative clinic from all 50 states. We next searched "wound center healing rates," which resulted in 8,120,000 websites, but the same results were provided as with the initial search. We found wound healing rates published online from clinics in 35 states. For the remaining 15 states, we then searched wound clinic healing rates state-bystate for Alaska, Hawaii, Oregon, Arizona, New Mexico, Colorado, Utah, North Dakota, South Dakota, Oklahoma, Louisiana, Mississippi, Georgia, Virginia, and Tennessee. Data were available for 44 clinics in 44 states. There were no clinics with healing rates published online in South Dakota, North Dakota, Utah, Oregon, Hawaii, and Alaska.

Clinic and wound healing data from 44 entities are summarized in Table 1. Reported healing rates were very high for all wounds (at least $80 \%$ ). Among the 40 centers that provided the percent of wounds healed, $34(85 \%)$ reported healing rates of at least 90\% (mean: 92\%; standard deviation [SD]: 4.5). Time-to-heal (provided as a mean or median) was available for 30 clinics and varied from 2.7 to 16 weeks, with the majority reporting healing within 4.3 weeks $(16 ; 53.3 \%)$.

Although 20 clinics (45.4\%) listed the number of providers, there were no data provided per individual provider. Only 10 clinics $(22.7 \%)$ reported the total number of patients, and only 2 clinics $(4.5 \%)$ reported the total number of wounds. Penrose-St. Francis Wound Care Clinic in Colorado Springs, CO was the only clinic to provide a mean time-to-heal for DFUs (11.1 weeks), in addition to the mean time-to-heal for all wounds ( 6.4 weeks). ${ }^{47}$ No other clinic provided DFU-related data. No clinics reported adverse events, data censoring rules, or the use of risk stratification, although The Center for Wound Healing and Hyperbaric Medicine Doctors Community Hospital in Lanham, MD, clarified that their data were based solely on patient adherence. ${ }^{14}$

\section{A "different reality" of wound healing rates reported by $\mathrm{RCTs}$}

We next utilized RCT data to establish the most optimistic wound healing rate possible.

We previously established that RCTs in wound care, almost without exception, exclude patients with significant comorbid diseases to evaluate the efficacy of the study agent, resulting in the ineligibility of more than half the wound care patient population. ${ }^{53}$ Virtually all prospective trials in wound healing are designed to allow wound epithelialization within 12-16 weeks and thus select a less sick patient population with relatively small, superficial ulcers. We recently confirmed this finding when comparing recent RCT data with the real-world patient data of a wound care research consortium. $^{54} \mathrm{We}$ found that the mean size of VLUs and DFUs of the consortium patients were, 


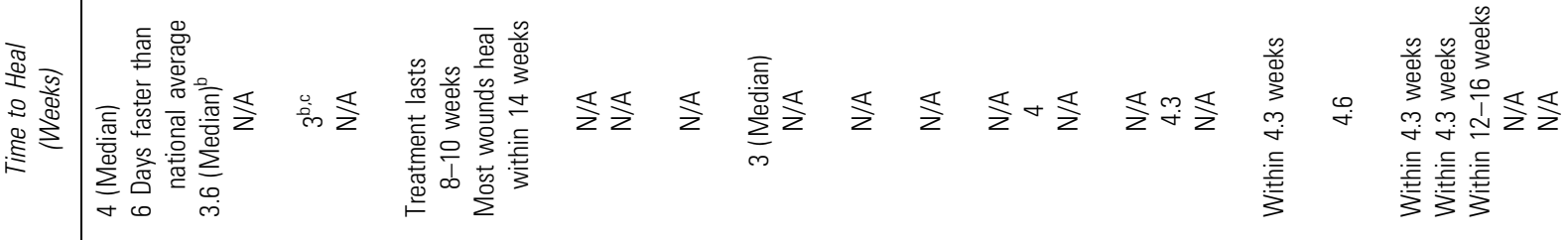

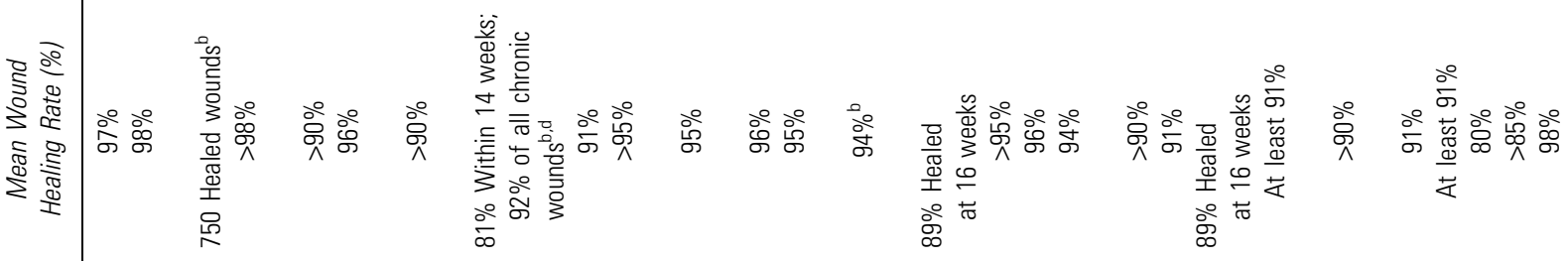

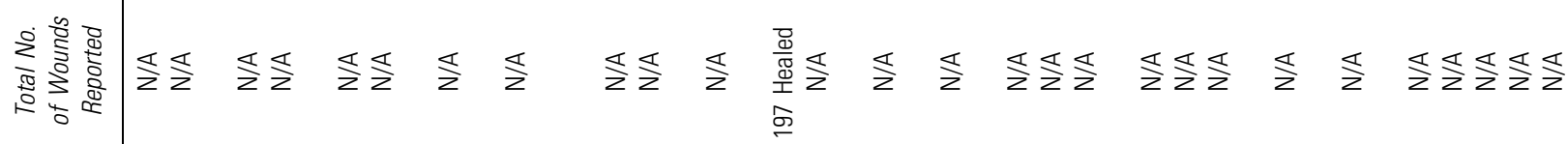

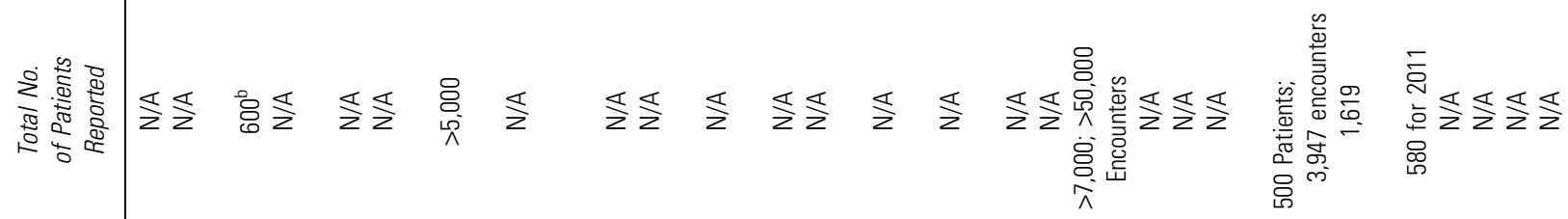

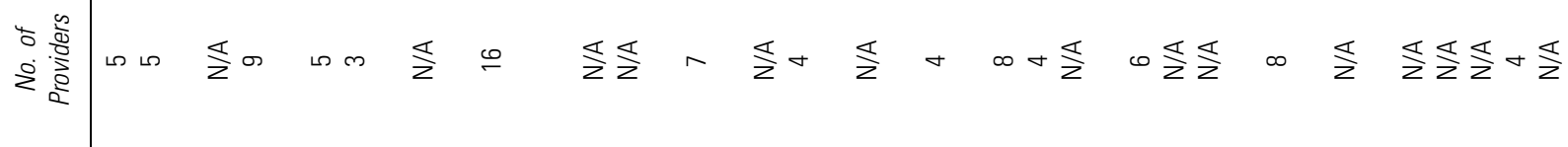

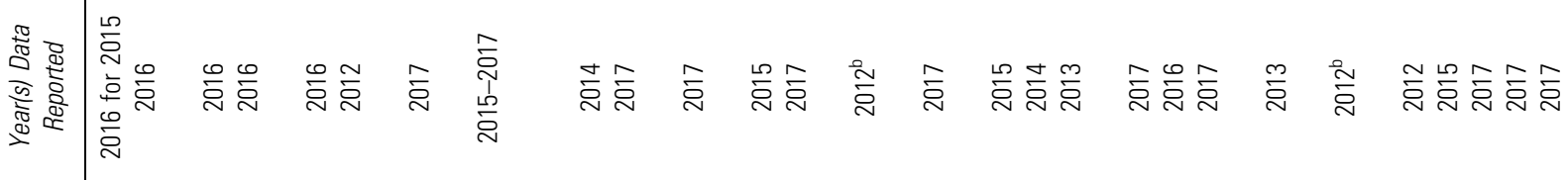

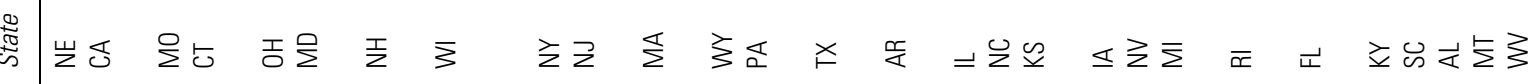

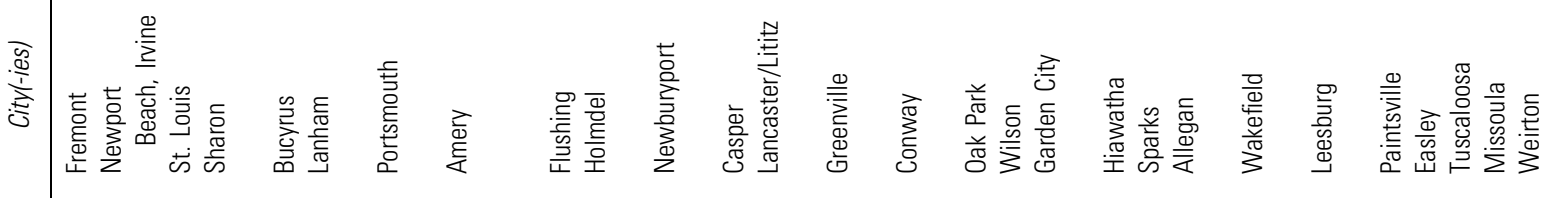

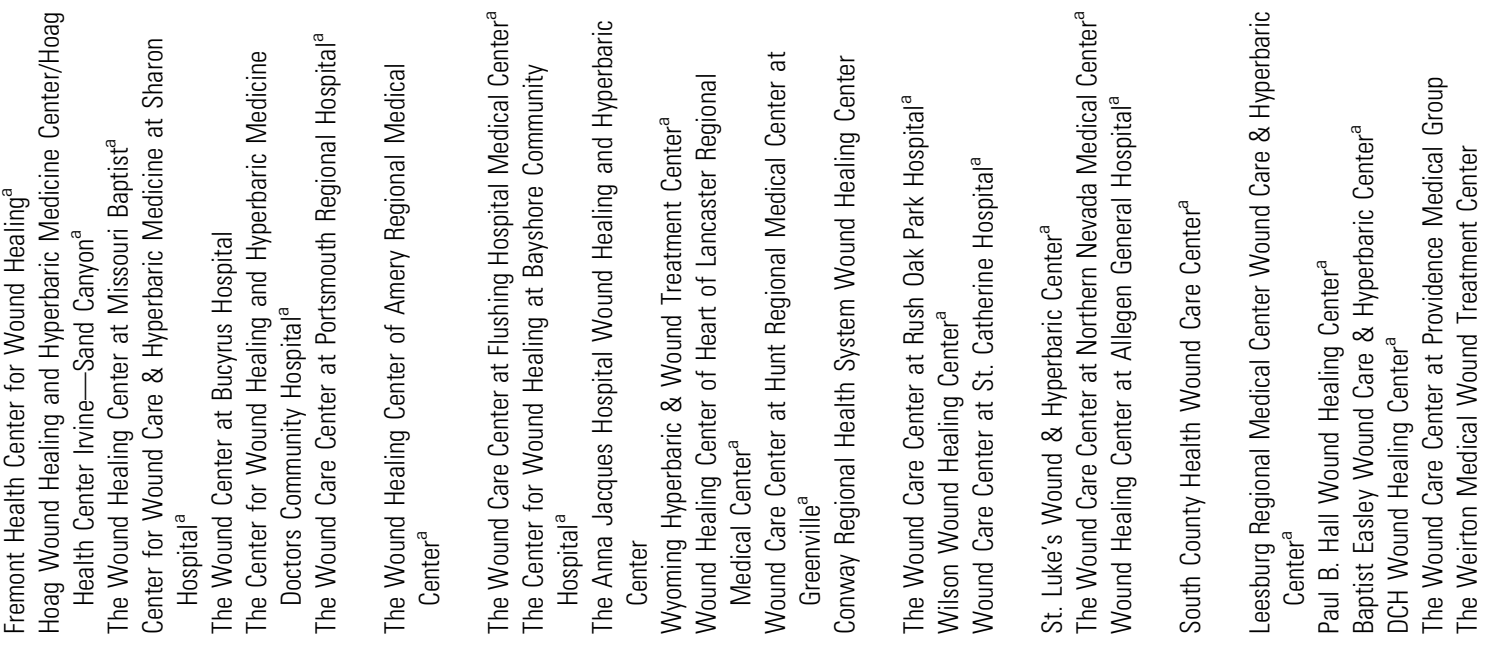




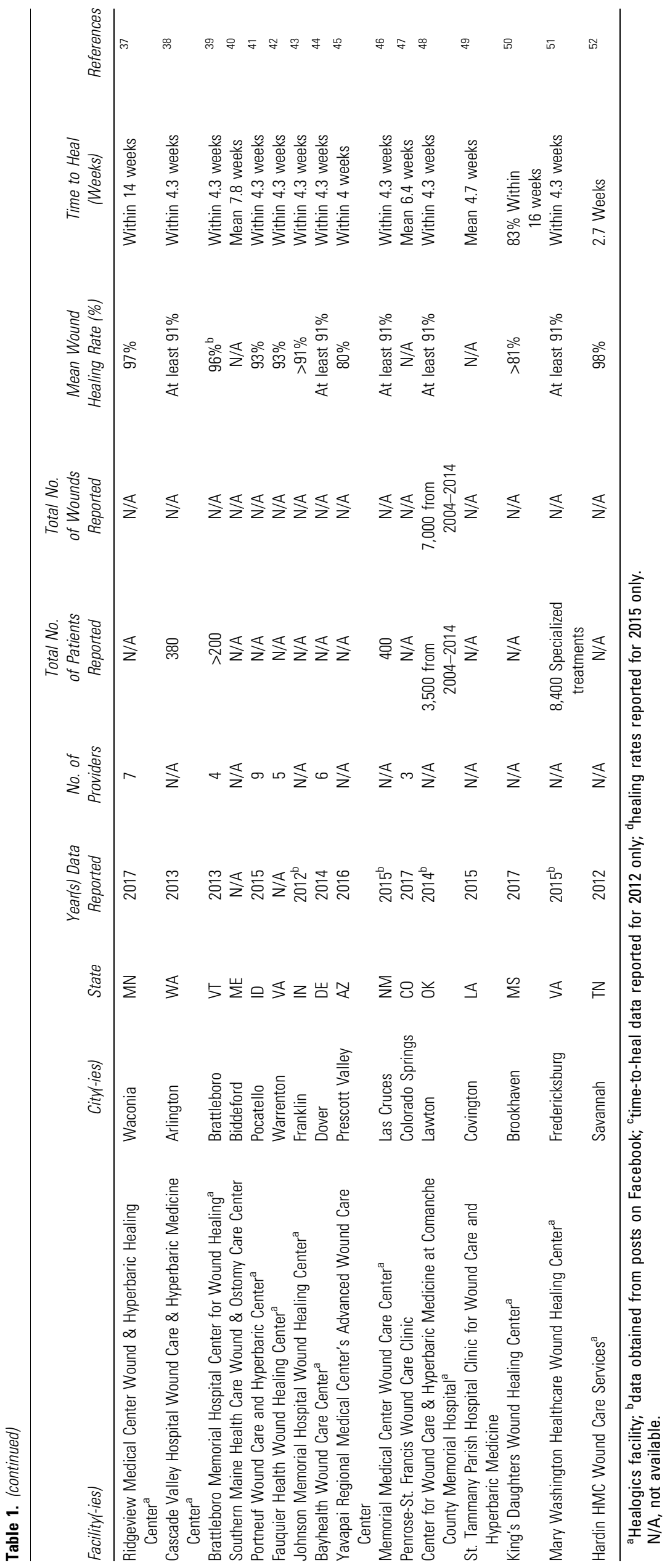




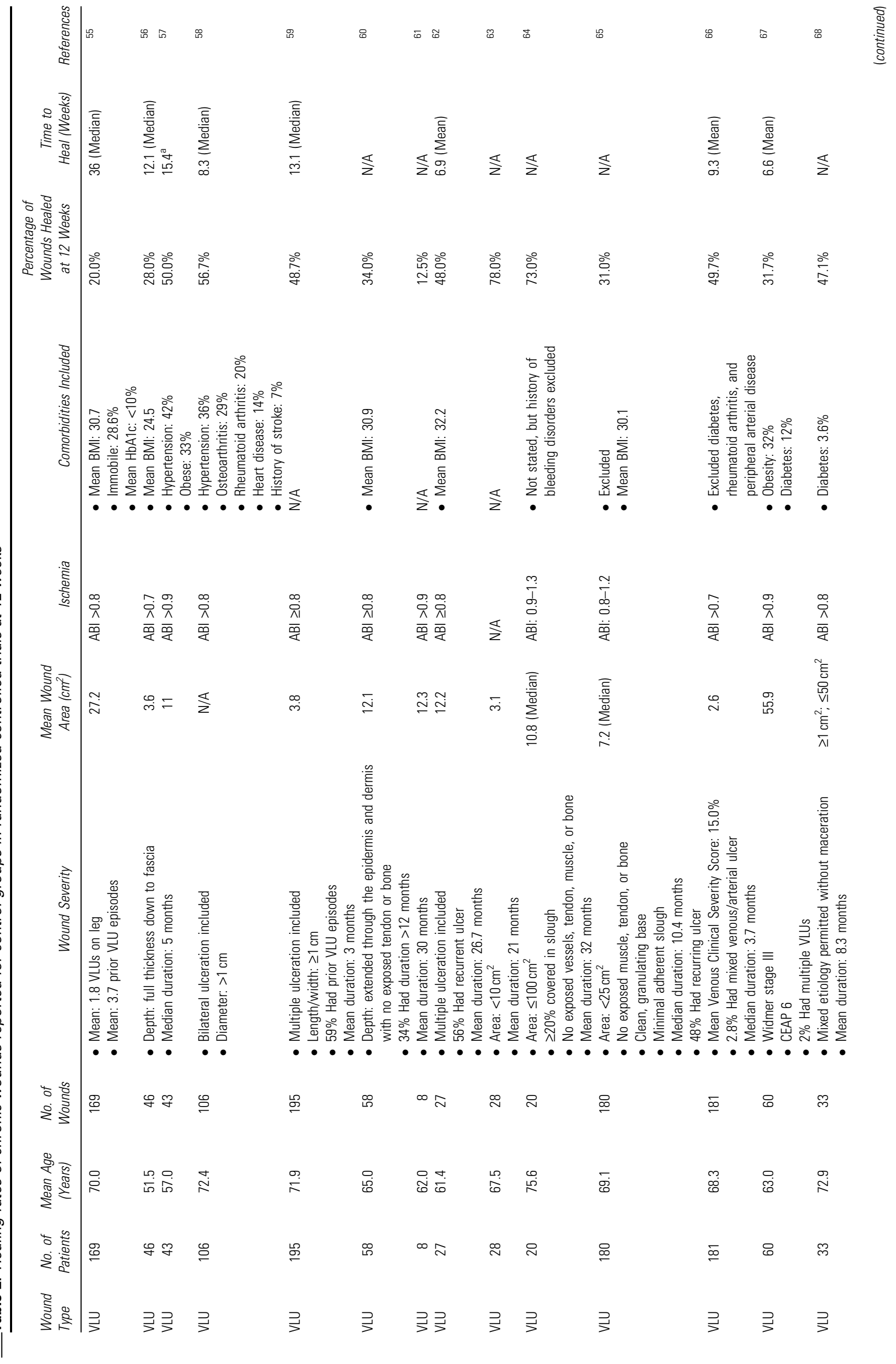




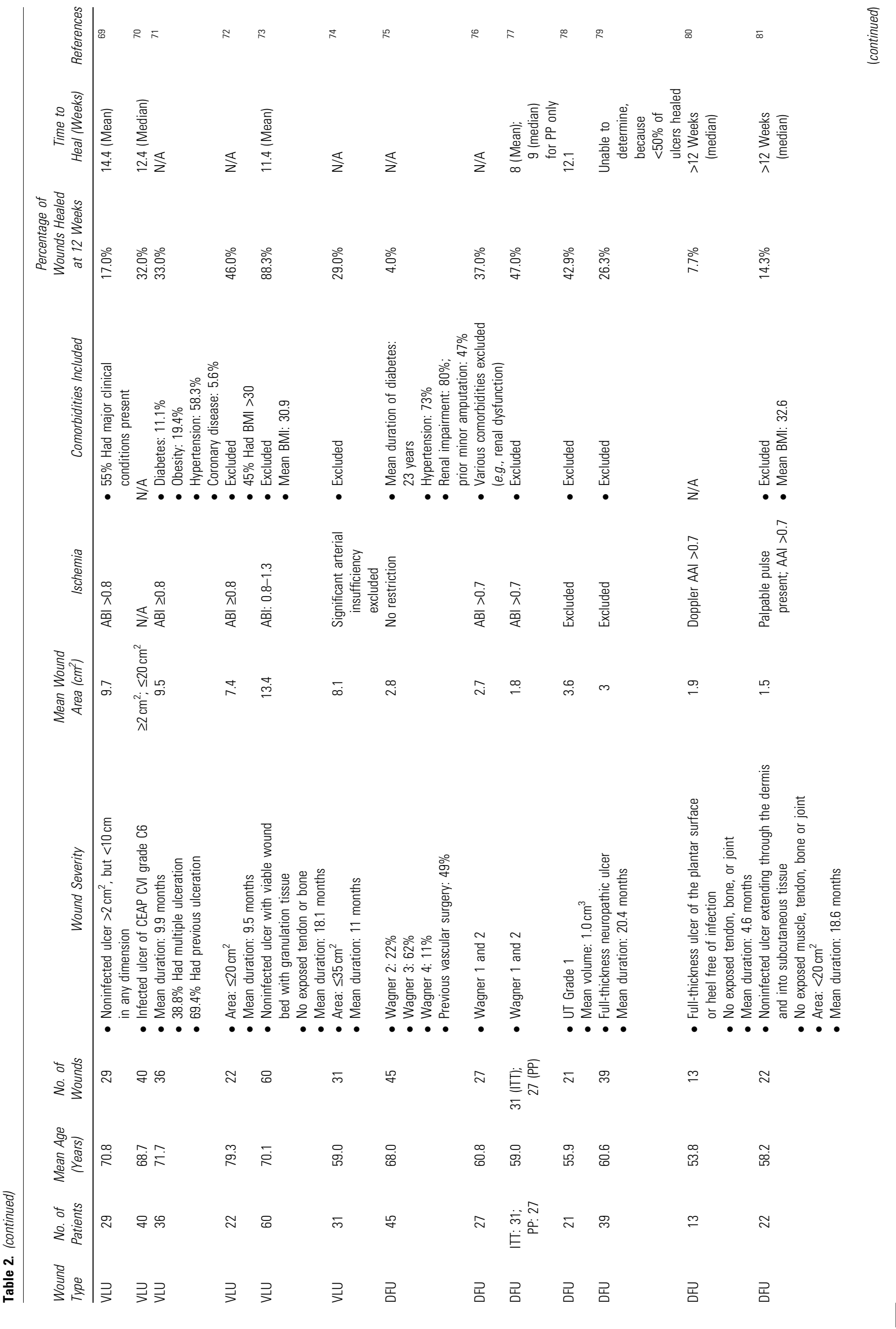




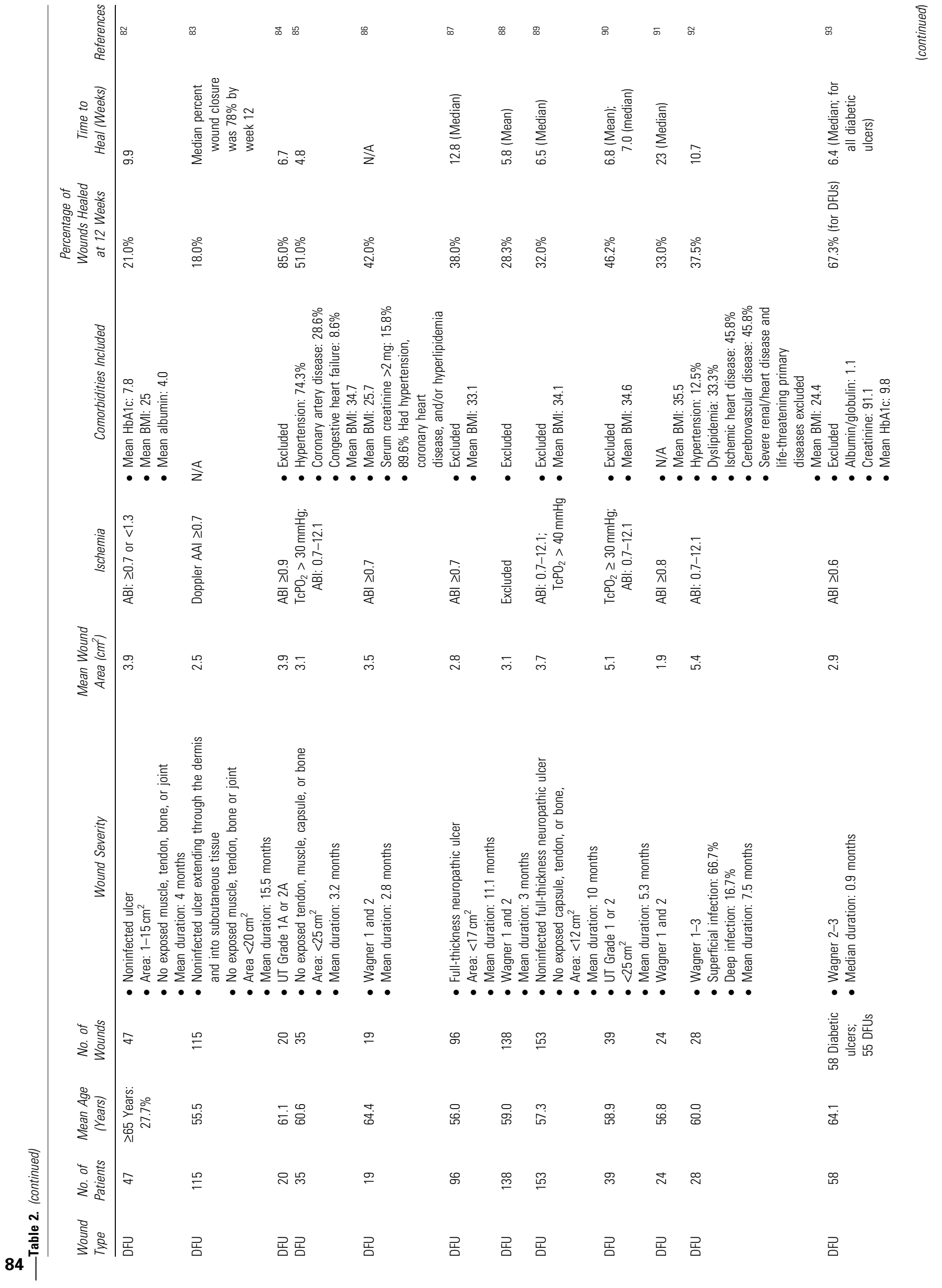




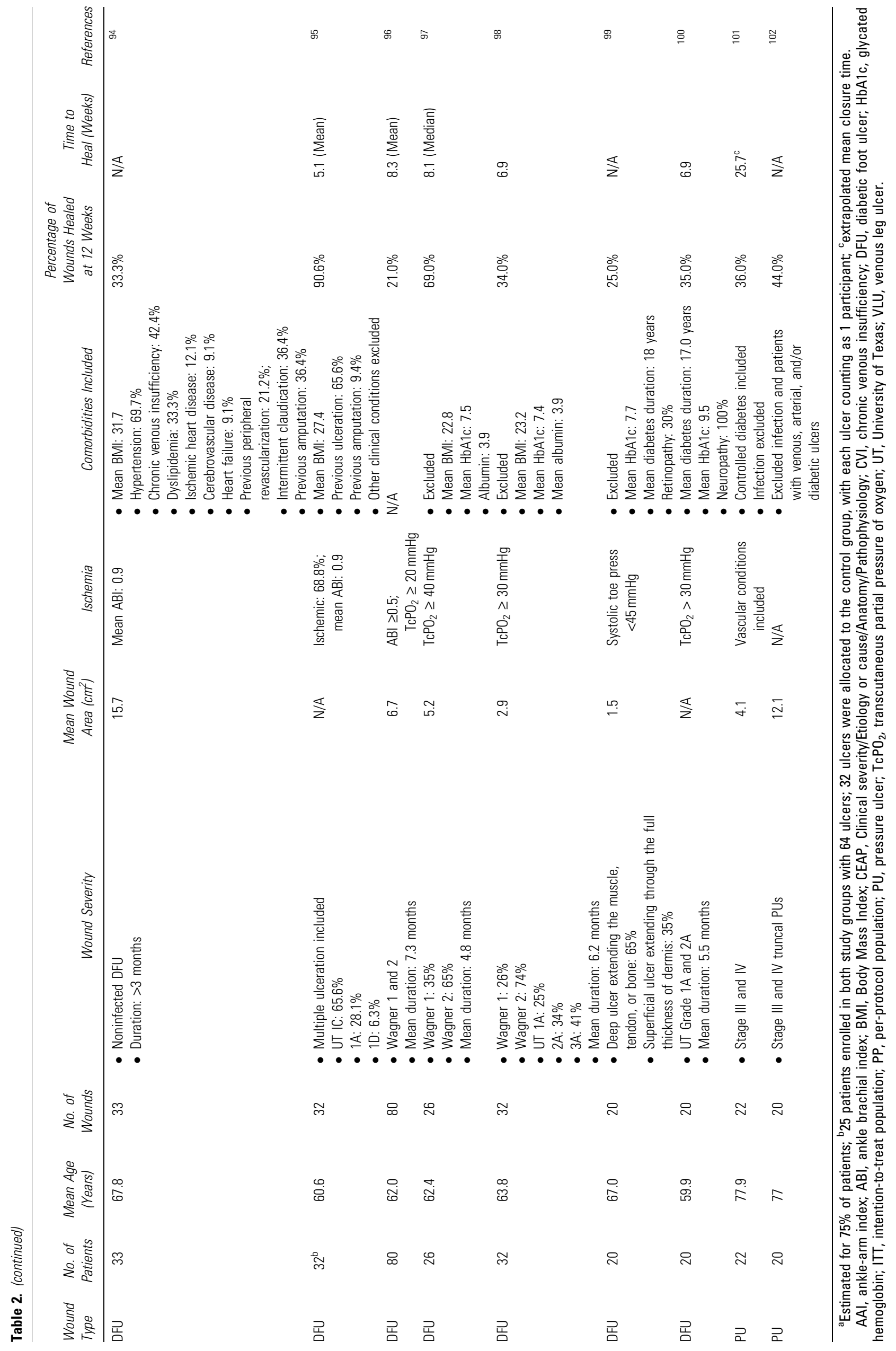


respectively, five and three times the size of the ulcers enrolled in the consortium RCTs. Furthermore, $43.6 \%$ of the consortium patients with DFUs had more severe ulcers graded at Wagner 3 or higher, when only Wagner 1 and 2 ulcers were eligible for the RCT.

We performed a search of 50 RCTs on PubMed using the following search terms: "diabetic foot ulcers," "venous leg ulcers," and "pressure ulcers" through February 1, 2017. We reviewed abstracts and selected articles that analyzed healing rates at 12 weeks for control/placebo groups. We collected data on the number of patients, mean age (years), the number of wounds, wound severity, mean initial wound area, whether or not ischemia was allowed, which comorbidities were allowed, the percent of wound healed at 12 weeks, and the time to heal.

Our literature search returned 48 RCTs meeting our search criteria, including 20 VLU trials, 26 DFU trials, and 2 pressure ulcer (PU) trials. There were 2,620 control subjects with 2,624 study wounds enrolled in all $48 \mathrm{RCTs}$. The data from these trials' control groups are summarized in Table 2 . The wound healing data contrasted strikingly with the data reported online by wound centers. The mean wound healing rate at 12 weeks among control subjects in the ideal environment of these trials was $40.0 \%$ (SD: $20.2 \%$; range: $7.7-$ $90.6 \%$ ), at least half of the rates reported by the wound centers. The mean VLU healing rate was 42.7\% (SD: $20.1 \%$; range: $12.5-88.3 \%$ ). The mean healing rates for DFU and PU trials were $37.9 \%$ (SD: 21.2\%; range: $4.0-90.6 \%$ ) and $40.0 \%$ (SD: 5.7\%; range: 36-44\%), respectively. The times to heal varied extensively for all wound trials and were provided as means or medians. The rate was as low as a mean of 5.1 weeks for a DFU trial $^{95}$ to as high as a median of 36 weeks for a VLU trial. ${ }^{55}$ None of the trials had a time to heal within the 4.3 weeks reported by majority of the wound centers.

What is even more alarming about the difference in healing rates between the RCTs and the wound centers is that we know many of the RCTs excluded patients with significant clinical comorbidities and ischemia, and the more severe wounds. It is reasonable to assume that the subjects enrolled in these RCTs were less sick than real-world patients and still, their healing rates were drastically lower that those reported online. It is likely that in the real world, among complicated patients (many of whom suffer from serious wounds and comorbidities), healing rates better than $40.0 \%$ are not, in fact, actually achievable.
Table 3. Percentage healing rates for the three most common types of chronic wounds at 12 weeks and regardless of time with mean follow-up times, based on data from the U.S. Wound Registry

\begin{tabular}{llll}
\hline Time Period & \multicolumn{1}{c}{ DFUs } & \multicolumn{1}{c}{ PUs } & \multicolumn{1}{c}{ VLUs } \\
\hline 12 Weeks & 30.5 & 29.6 & 44.1 \\
No period of time specified & 45.1 & 43 & 56.9 \\
Mean follow-up time & 19.7 (36.17) & 24.5 (48.97) & 16.1 (33.56) \\
$\quad$ in weeks (SD) & & & \\
\hline
\end{tabular}

$\mathrm{SD}$, standard deviation.

\section{Evaluation of real-world quality data: saying what we mean}

To determine true wound healing rates, we cannot apply RCT exclusion criteria, because we need to understand and include all real-world patients. Patients with chronic wounds are older and very sick. ${ }^{54,103}$ Our previous research of USWR real-world data demonstrated that, if all patients are reported, the national wound healing rate is $\sim 66 \%$. $^{103,104}$ We next evaluated uncensored realworld data from the USWR.

The general methodology for obtaining datasets suitable for wound care analysis has been previously described. ${ }^{103,105}$ The dataset analyzed included all DFUs, VLUs, and PUs with in-service visit dates from September 28, 2001, through December 1, 2016, comprising 71,957 DFUs, 77,891 PUs, and 99,588 VLUs. To account for one-time (consultation) visits and patients whose wounds were still in service (and thus without outcomes), 17,662 wounds that only had 1 visit and 11,447 wounds that were still in service were deleted from the dataset leaving 62,964 DFUs, 66,577 PUs, and 97,420 VLUs for analysis. Outcomes were determined for percentage of wounds healed at 12 weeks, using a window of \pm 3 days around 84 days after the first clinic visit in which the wound was examined, and percentage of wounds that ever healed without time limit. The algorithm employed to determine whether the wound was healed has been previously reported. ${ }^{105}$ The results show that at 12 weeks, about $30 \%$ of DFUs and PUs were healed, whereas nearly $45 \%$ of VLUs were healed (Table 3). Without time constraints, substantially more wounds were healed, but VLUs have the highest percentage of wound closure by wound type at $56.9 \%$ healed.

\section{DISCUSSION}

The "war against reality" and the casualty of the honest wound healing rate

When it comes to outcome data, both providers and consumers should be cautioned that the 
internet is currently a maddening Wonderland. Without a standardized risk stratification method, there is considerable pressure to inflate healing rates on websites and social media accessed by consumers, because not to do so will make the practitioners attempting accurate reporting appear less clinically capable. ${ }^{103}$ Consequently, data are vetted by reclassifying patients with wounds that do not heal under palliative or complex care, thereby removing these patients from the denominator for public reporting. Similarly, patients who do not return to the clinic after 30 consecutive days are reported as lost to follow-up and removed from the dataset. ${ }^{106}$

Wound healing rates publicly reported online and directed at healthcare consumers consistently listed rates of $80 \%$ or better (mean: $92 \%$ ), with the majority reporting. No reporters provided transparency of data censoring practices or included a discussion of adverse event rates. Indeed, none of these entities acknowledged that poor outcomes ever occurred. Also of importance is that not a single center explained how it defined a healed wound. The lack of clearly defined wound outcomes is a challenge to data reporting. ${ }^{105,107}$ The U.S. Food and Drug Administration (FDA) defines a healed wound as reepithelialized skin without drainage or dressing requirements confirmed at 2 consecutive visits 2 weeks apart, ${ }^{108}$ yet in a review of 176 articles reporting wound outcomes, $19 \%$ did not provide a clear definition of a healed wound. ${ }^{107}$ Ultimately, "healing" may not be the ideal measure for quality reporting given the fact that real-world wounds may require many months to accomplish complete closure. It may be that intermediate outcomes can be identified which are better. It is important to reach a consensus regarding patient exclusions, as further explained at the end of this section. For example, the Wound Healing Index (WHI) is currently available for seven major wound types. Wounds that do not fit one of these categories will have to be excluded from reporting since it will not be possible to stratify them across different sites. A more general risk stratification system could likely be developed for the less common ulcer types (e.g., sickle cell ulcers), if funding were available, but given the general lack of investment in wound healing research, additional risk models are not on the horizon. It should be noted that an online Google search for wound healing rates does not produce random results, but rather uses industry ranking and device-specific algorithms that are tailored to the consumer preferences of each device using Google. Therefore, the selected 490 search results provided involve a degree of selec- tion bias. The consistently high healing rates reported online can be attributed to the fact that most of the centers $(35 / 44 ; 79.5 \%)$ identified by our online search are Healogics facilities, which target a national healing rate of $92 \% .{ }^{21}$ Based in Jacksonville, FL, Healogics, Inc. is the largest for-profit wound care operator in the United States, with nearly 800 affiliated facilities and more than 3 million wounds treated. ${ }^{109}$ Healogics centers strive for a patient satisfaction rate higher than $92 \%$ and a healing rate of at least $91 \%$ in under 30 median days. ${ }^{110}$ These healing rates are unachievable in the absence of data censoring rules designed to exclude patients solely because they did not heal, a statistical method truly worthy of Lewis Carroll.

All publicly reported information also indicated that healing would be achieved within a period of time similar to those seen in clinical trials (e.g., 12 weeks), with the majority of entities citing a time to heal of within 4.3 weeks. We do not, however, know what reporting timeframe was used. While 12 weeks is the recommended follow-up period for a clinical study, this timeframe should vary by wound type and other patient and wound characteristics. ${ }^{111}$ It is important to note that some facilities reported mean times to heal, others reported median times to heal, and some did not specify. This heterogeneity in reporting time to heal was also demonstrated by the RCTs analyzed and is a common issue that renders clinically relevant comparisons impossible. ${ }^{112}$ Another issue that complicates the quality and integrity of time-toheal data is that they are usually reported from outpatient wound clinics, with few patients requiring hospitalization and even fewer requiring subacute care, and do not necessarily encompass the entire episode of care. ${ }^{106}$ For example, Ennis et al. reported a 5-week time to heal of a VLU treated at an outpatient clinic. ${ }^{106}$ However, the entire continuum of care lasted 69 weeks, when they counted prior care in the primary care setting, a wound clinic, home healthcare, subacute care, and hospitalization. The authors further pointed out that when the same clinical team followed and provided the same wound management program in both the outpatient and subacute settings, the outpatient healing rates were $72-74 \%$, whereas only $41.6-45.9 \%$ of patients healed in the subacute programs. ${ }^{113}$ Importantly, only $10 \%$ of their patients were admitted for subacute care; these were sicker and more complex patients who could not be expected to have healing rates similar to those treated at an outpatient wound clinic.

To improve the reporting of outcomes that better reflect the entire episode of care and reduce the 
effect of the clustering of observations (when patients are treated at multiple sites of care and/or by multiple providers), ${ }^{105}$ providers need to improve the reporting of what happens to patients if they stop visiting their particular clinic. There are a variety of reasons that patients are not counted in wound healing denominator calculations, with patients

- Only visiting the clinic for consultations, not treatment

- Lost to follow-up

- No longer visiting the clinic after 1 or 2 months

- Moving outside the clinic's geographical coverage area

- Transferred to another facility or care setting (i.e., hospital, acute care, long-term care, nursing home, and home healthcare).

- Dying, which can occur especially among patients with more severe DFUs and comorbidities

- Simply deciding to no longer return to the clinic and/or continue care.

Wound outcome data absolutely must consider the site and setting of care, the wound management and standard of care undertaken, the point at which providers are involved in the continuum of care, and risk stratification of patients and wound complexity and severity to report honest rates. ${ }^{106}$

RCTs of uncomplicated, small ulcers of different wound types among relatively healthy subjects consistently reported mean healing rates around $40 \%$ (Table 2), although these rates varied widely across trials (range: 7.7-90.6\%). Based on uncensored USWR data (Table 3), the healing rate of DFUs among typical patients at hospital-based outpatient wound centers may be as low as $30.5 \%$. Based on real-world data and RCTs, healing rates over $90 \%$ as publicly reported can be achieved only by creating extreme censoring rules, which are not likely to fall within acceptable standards of data management, but can be summarized as, "We are all mad here." Truth is not the only casualty of this system. By reporting that nearly all wounds heal, we are unable to elucidate the relative contribution of specific interventions, many of which are being called into question on the eve of capitated or episode-based payments. Indeed, inflating healing rates makes it is nearly impossible to develop episode-based payment models, a task upon which the future survival of the field of wound care may depend.
How shall we reconcile these diverse observations to allow for useful reporting of wound healing rates and other quality measures? Inflated healing rates accessed by consumers online are for marketing purposes only and are not reported to CMS or any other quality organization. Both CMS and the National Quality Forum (NQF) work diligently to standardize quality measures. CMS requires that duplicative or overlapping measures undergo "measure harmonization," which requires the measure sponsors to work collaboratively to resolve differences and develop a single measure to be implemented. ${ }^{114}$ However, CMS has not developed any quality measures focused on wound outcomes at the national level. QCDRs were intended to allow specialty societies to fill measure gaps. Since wound care is not a recognized medical specialty, it lacks a consensus-forming body. The USWR has tried to fill the measure gap in wound care by creating the WHI and developing outcome measures. Success has been limited, because, under MIPS, practitioners may choose which quality measures they wish to report and have no incentive to tackle the challenge of risk-stratified outcome reporting when easier (although less relevant) measures suffice.

Therefore, to improve the transparency of the public reporting of data and transform healthcare culture, the questions are as follows: who should publicly disclose quality data and patient information and how should it be done? ${ }^{8}$ USWR data suggest that rather than reporting unbelievably inflated healing rates, or reporting uncensored data with so many confounding factors as to be uninterpretable, some middle ground is possible to achieve quality measure reporting. It is possible to use survival approaches to wound healing outcomes that include right censoring of patient wound data. Based on the USWR data reported herein, it seems reasonable to exclude from outcome reporting the following wounds:

- Wounds in patients transferred to another clinic or setting for treatment so that their outcome is not known; however, the challenge here is that sicker patients with more complex wounds are more likely to be transferred to an acute care facility because of complications

- Wounds in patients who are lost to follow-up, if their final outcome is not known

- Wounds in patients who make fewer than three visits within some clinically relevant timeframe (e.g., 4 weeks). 
Wounds in patients who die in service may need to be reported as having the adverse event of death, although further discussion on this point is warranted. Although provider performance should not be judged by the outcome of patients they did not finish treating, nearly complete wound healing is commonly observed for many patients before death. Public reporting should also evaluate provider performance based on their caring of the sickest patients. More transparent and honest wound healing outcome data will follow after the quality of care is measured based on the percentage of healed patients when risk stratification is used to determine their healing likelihood. ${ }^{115}$ By using risk stratification, we could identify which practi- tioners or institutions may be providing exemplary care, not by reporting healing rates over $90 \%$, but by a healing rate of, for example, $50 \%$ among wounds with only a $30 \%$ predicted likelihood of healing. A study is underway that will use risk stratification to assess provider performance.

\section{Criteria to reporting real-world quality data}

We recently published the "ABCs of Registries," a list of reporting standards for publications of realworld wound registry data to minimize the sources of bias. ${ }^{103}$ These criteria are based on the collection of all patient and wound data at the point of care to be transmitted directly to an electronic health record, which implements a risk stratification model

Table 4. The current limitations to publicly reporting wound healing rates and the criteria needed to report honest healing rates

\begin{tabular}{|c|c|}
\hline Limitation & Criteria to Report Honest Wound Healing Rates \\
\hline $\begin{array}{l}\text { (1) Lack of standardized definitions for wound } \\
\text { outcomes }\end{array}$ & $\begin{array}{l}\text { Healed wound }=\text { completely closed wound confirmed } \\
\text { by two visits } 2 \text { weeks aparts. }{ }^{105}\end{array}$ \\
\hline (2) Lack of timeframe (by wound type) ${ }^{103,105,106}$ & $\begin{array}{l}\text { Healing rates to be reported based on percent healed } \\
\text { at } 1 \text { year; time to heal to vary by wound } \\
\text { type. }\end{array}$ \\
\hline $\begin{array}{l}\text { (3) Variation in diagnostic codes across wound } \\
\text { types }{ }^{103,105}\end{array}$ & Define wound types. \\
\hline
\end{tabular}
types $^{103,105}$

\author{
Comments \\ Amputations are considered nonhealed wounds. ${ }^{105}$ \\ The time to heal of a DFU may be based on 3-6 \\ months, whereas a VLU may be based on 1-2 \\ years. \\ Because wounds are symptoms of an underlying \\ disease, they often refuse neat categories. Many \\ patients are on immunosuppressives, many pa- \\ tients with leg ulcers have both venous and \\ arterial disease; $33.1 \%$ of patients with chronic \\ wounds that are not DFUs have diabetes. ${ }^{104}$ \\ Diagnosis is difficult. ${ }^{105}$ \\ Healing rates at wound centers can be delayed when \\ proper standard of care is not utilized, which \\ reflects poorly on provider performance. In 2009, \\ USWR data demonstrated that only $6 \%$ of \\ patients with DFUs and $17 \%$ of patients with VLUs \\ receive adequate, respective standard of care of \\ offloading and compression bandaging. ${ }^{116}$ These \\ rates improved by 2015 , with $56 \%$ of DFUs \\ adequately offloaded and $88.7 \%$ of VLU ade- \\ quately compressed at each visit. ${ }^{117}$ \\ These variables are used in risk stratification.
}

Define wound care protocols. ${ }^{105,106}$

\title{
applicable)
}

are not defined

(5) Lack of key wound, patient, and healing factors

(6) Lack of risk stratification for patients and wounds

(7) Lack of data censoring rules
Include wound area, wound severity wound duration, patient age, presence of ischemia, comorbidities, and adverse events. ${ }^{103,105}$

Need to report whether any risk stratification and/or severity indices was used for patients and wounds and identify model used. ${ }^{103,105,106}$

Need to report patients/wounds not included in the wound healing rate denominator. ${ }^{103,105}$

Need to report the healing rate based on the point along the patient's entire episode of care. ${ }^{106}$

Need to report the annual number of patients and wounds treated, the number of providers/facility, and data by provider.
Providers will be more motivated to report honest healing rates when they are based on the patient's likelihood of healing and not just on the proportion of wound healed.

Providers must do a better job of tracking patients who no longer return to clinic. In the future, wound registries that could be integrated into the Medicare dataset would have mechanisms in place to track patients across sites of care.

Patients may also have multiple wounds that are not all counted in the healing rates.

Same comment as in No. 7.

High volume and specialized centers will have weighted healing rates compared to low volume, less experienced centers. ${ }^{106}$ 
that creates matched cohorts for different wound types. We also published 13 guidelines based on the RECORD statement to improve the reporting of wound care analyses derived from electronic health records and registries to minimize biases and make more realistic comparisons of the results and outcomes. ${ }^{105}$ Similar criteria are also needed for the public reporting of real-world data. The majority of our guidelines for reporting wound care analyses are also applicable to public reporting of outcome data. In Table 4, we have summarized the criteria needed to publicly report wound healing rate data based on the current limitations demonstrated by this study.

\section{Conclusions}

The transition of Medicare physician payment to an entirely new structure in 2017 went almost unnoticed by healthcare professionals, perhaps, in part, due to all the other simultaneous cultural and political upheavals. In addition, CMS eased the transition with a "Pick Your Pace" program that allows practitioners to protect their 2017 Medicare Part B payments by reporting (e.g.) only one quality measure, postponing the reality of this new program until 2018. ${ }^{118}$ Although the focus of this article is not the arcane details of MIPS, fully implemented, wound care practitioners are not likely to be successful without utilizing measures that are relevant to their practice. In 2016, the USWR set national benchmark rates for offloading of DFUs, compression of VLUs, and arterial screening of leg ulcer patients, the components of its "Do the Right Thing ${ }^{\mathrm{TM}}$ " initiative. ${ }^{117} \mathrm{CMS}$ has given the USWR permission to publicly report physician performance data for these three quality measures on the USWR website. Physicians have begun to report to CMS the data on risk-stratified DFU and VLU outcome measures, and the USWR will begin public posting of national wound healing rates once outcome measure data have met CMS reporting standards. On the eve of public reporting of patient outcomes like wound healing rates, we must abandon the uncommon nonsense of a national healing rate of $92 \%$, which cannot be reasonably believed, based on the healing rates documented in prospective trials (Table 2). Some data censoring is necessary to account for numerous factors, including patients who are lost to follow-up. After censoring, wounds must (and will) be risk adjusted as a matter of federal law, if clinicians wish to use relevant QCDR measures to satisfy MIPS/PQRS reporting requirements and thus avoid cuts in Medicare Part B payments. This is the only approach that can identify outliers among providers in either direction (superior or inferior), establish the need for certain advanced therapeutics, or provide justification for high resource use patients.

While wound risk adjustment continues to require more research, provider data must now be reported on Physician Compare. Many other reporting parameters should be decided, preferably by consensus, and most logically facilitated through the Alliance of Wound Care Stakeholders in similar process as were the USWR quality measures. Some basic rules for publicly reporting data have been proposed in this article, but others are needed, including the minimum number of wounds in each category to allow reporting. It is also hoped that the Wound-Care Experts/U.S, FDA-Clinical Endpoints Project currently underway will identify metrics other than wound healing or closure, which can be formulated into valuable wound outcome quality measures. ${ }^{119}$ During the first phase of this ongoing study, 628 wound experts and researchers identified 15 potential endpoints that will be studied further in the research phase to provide evidence supporting their use in regulatory decision-making. From these endpoints, there are four potential primary outcomes that have been content validated as both clinically relevant and patient centered: reduced amputation, reduced economic burden, improved function and ambulation, and improved quality of life. ${ }^{119}$ Ironically, in 2017, CMS rejected the USWR "Patient Reported Wound related Quality of Life" QCDR measure, which had been reported by only one physician in the United States in 2016, in part due to the uncompensated cost of implementing a patientreported measure, revealing the wide gulf between those outcomes we say we value and those we are actually willing to support. Which way we go from here does depend on where we want to go. If the wound care community wants to survive healthcare reform, then it will be through risk adjustment and a transparent way of reporting wound healing rates, and other meaningful wound outcomes, including patient-reported outcomes. In the absence of federal investment in this vexing problem, it is in the best interest of manufacturers to fund improvements in the public reporting of outcomes through quality measures, since this is the way by which the value of therapeutic interventions can best be understood in the real world. When it comes to the reporting of healing rates, we agree with Alice, "It would be so nice if something made sense for a change."

\section{SUMMARY}

In this review, we compare real-world healing rates from the USWR, a QCDR, with RCTs and 
publicly reported data and develop criteria for honest reporting of wound outcomes, a requirement of CMS under the new Quality Payment Program. We demonstrate how real-world and RCT data provide convincing evidence that most patients (55-70\%) do not heal their wounds, in contrast with a mean publicly reported healing rate of $92 \%$. It is likely that in the real world, among complicated patients, healing rates better than $40.0 \%$ are not achievable.

By federal law, if quality data are reported by any QCDR, at least one outcome measure must be reported and must be risk adjusted. Without a standardized risk stratification method, there is considerable pressure to inflate healing rates on media accessed by consumers, because not to do so will make the practitioners attempting accurate reporting appear less clinically capable. Some data censoring is necessary to account for numerous factors, including patients who are lost to follow-up. However, wounds must (and will) be risk adjusted, if clinicians wish to use relevant QCDR measures to satisfy reporting requirements and thus avoid cuts in Medicare Part B payments. By reporting that nearly all wounds heal, we are unable to elucidate the relative contribution of specific interventions, many of which are being called into question on the eve of capitated or episode-based payments. If the wound care community wants to survive healthcare reform, then it will be through risk adjustment and a transparent way of reporting wound healing rates and other meaningful wound outcomes, including patient-reported outcomes.

\section{ACKNOWLEDGMENT AND FUNDING SOURCE}

This study was funded by the USWR.

\section{AUTHOR DISCLOSURE AND GHOSTWRITING}

C.E.F.: Chief Medical Officer of Intellicure and shareholder, Executive Director of the USWR (uncompensated); K.A.E.: paid consultant of Strategic Solutions, Inc. during this study; M.J.C.: unpaid consultant of the USWR to this study. The content of this article was expressly written by the authors listed. No ghostwriters were involved in the writing of this article.

\section{TAKE-HOME MESSAGES}

- Wound outcomes must be reported under the new Quality Payment Program, and when quality data reported are by a OCDR, at least one outcome measure must be reported and risk adjusted.

- A risk-stratification tool alleviates the pressure practitioners face inflation in their healing rates, by preventing those who care for the sickest patients from being penalized by appearing to have poorer outcomes than their peers.

- While wound care provider entities publicly report online a mean healing rate of $92 \%$, it is likely that in the real world, among complicated patients, healing rates better than $40.0 \%$ are not achievable.

- Criteria needed to report honest healing rates include standardized definitions of "healed wound" and "healing rate," defined wound care protocols, the inclusion of patient and wound demographics, and the need to report whether any risk stratification was used, if any patients/ wounds were not included in the wound healing rate denominator, at what point the healing rate is along the entire episode of care, and the total number of patients/wounds, disaggregated by provider and facility.

- Some basic rules for publicly reporting data have been proposed herein, but other parameters are needed, which should be determined by consensus in the wound care community to ensure that transparent and riskstratified wound outcome data are reported.

\section{ABOUT THE AUTHORS}

Caroline E. Fife, MD, did her residency in Family Medicine at the University of Texas, Southwestern in Dallas, followed by a Fellowship in Undersea and Hyperbaric Medicine (UHM) at Duke University, where she was subspecialty board-certified in UHM. She was Professor of Medicine in the Division of Cardiology at the University of Texas Health Science Center in Houston (1990-2013). A Certified Wound Specialist since 1998, she is now the Medical Director of the St. Luke's Wound Care Clinic in The Woodlands, Texas, and a Professor of Geriatrics at Baylor College of Medicine in Houston. Dr. Fife is also the Chief Medical Officer of Intellicure, a Texas-based software company, and is the Executive Director of the USWR, a nonprofit organization recognized by CMS as a QCDR. Kristen A. Eckert, MPhil, is a certified Medical Writer and Editor (University of Chicago, 2016) with more than 10 years of experience working in global health programs and has contributed to dozens of peer-reviewed medical publications in wound care and other pathologies. Marissa J. Carter, PhD, MA, has an MA in biochemistry from Oxford University and a $\mathrm{PhD}$ in chemistry from Brandeis University. She is an evidence-based medicine reviewer, biostatistician, and epidemiologist and is President of Strategic Solutions, a company that designs, runs, and analyzes clinical trials, most commonly in wound care. 


\section{REFERENCES}

1. Medicare.gov. Physician compare. March 3 , 2017. www.medicare.gov/physiciancompare/ (last accessed March 13, 2017)

2. Centers for Medicare \& Medicaid Services. Quality payment program. What's the MeritBased Incentive Payment System (MIPS)? https:// qpp.cms.gov/learn/qpp (last accessed March 13, 2017)

3. U.S. Wound Registry. USWR overview. 2017. https://uswoundregistry.com/About-Overview (last accessed March 13, 2017).

4. U.S. Wound Registry. Quality measures. 2017. https://uswoundregistry.com/QualityMeasures (last accessed March 13, 2017).

5. American Taxpayer Relief Act of 2012 (ATRA). Pub. L. 112-240 (2013).

6. The Society of Thoracic Surgeons. What is risk adjustment? 2017. www.sts.org/node/2256 (last accessed March 13, 2017).

7. Centers for Medicare \& Medicaid Services. Quality data and physician compare. June 5, 2016. www.cms.gov/Medicare/QualityInitiatives-Patient-Assessment-Instruments/ physician-compare-initiative/Quality-Data-andPhysician-Compare-.html (last accessed March 14, 2017).

8. Lee V. Transparency and trust—online patient reviews of physicians. N Engl J Med 2017;376:197-199.

9. Fremont Health Center for Wound Healing. 2016. www.fremonthealth.com/woundcenter (last accessed January 9, 2017).

10. Hoag Wound Healing and Hyperbaric Medicine Center/Hoag Health Center Irvine-Sand Canyon. 2016. www.hoag.org/specialties-services/otherprograms-services/wound-healing-hyperbaricmedicine (last accessed January 9, 2017).

11. The Wound Healing Center at Missouri Baptist 2016. www.missouribaptist.org/MedicalServices/ WoundHealingCenter.aspx (last accessed January 9,2017$)$.

12. Center for Wound Care \& Hyperbaric Medicine at Sharon Hospital. 2016. http://sharonhospital .com/departments/woundcare-hyperbaric (last accessed January 9, 2017).

13. The Wound Center at Bucyrus Hospital. 2016 http://avitahealth.org/dwp/nmp/services/woundcenter (last accessed January 9, 2017).

14. The Center for Wound Healing and Hyperbaric Medicine Doctors Community Hospital. 2012. www .dchweb.org/specialties-services/center-woundhealing-and-hyperbaric-medicine/faqs (last accessed January 9, 2017).

15. The Wound Care Center at Portsmouth Regional Hospital. 2017. http://portsmouthhospital.com/ service/wound-healing (last accessed January 9, 2017).

16. The Wound Healing Center of Amery Regional Medical Center. 2017. www.amerymedicalcenter .org/locations/wound_healing_center.aspx (last accessed January 9, 2017).

17. The Wound Care Center at Flushing Hospital Medical Center. 2014. http://flushinghospital .org/clinical_services/woundcare.html (last accessed January 9, 2017).

18. The Center for Wound Healing at Bayshore Community Hospital. 2017. http://bayshorehospital .org/B/services/CenterForWoundHealing (last accessed January 9, 2017).

19. The Anna Jacques Hospital Wound Healing and Hyperbaric Center. 2017. www.ajh.org/servicesand-departments/12-wound_healing_hyperbaric_ medicine/view-department (last accessed January 9, 2017).

20. Wyoming Hyperbaric \& Wound Treatment Center. 2015. https://wyomingmedicalcenter.org/ clinic/wyoming-hyperbaric-wound-treatment (last accessed January 9, 2017).

21. Wound Healing Center of Heart of Lancaster Regional Medical Center. 2017. www.lancaster medicalcenters.com/wound-healing-centers (last accessed January 9, 2017).

22. Wound Care Center at Hunt Regional Medical Center at Greenville. 2017. www.huntregional .org/our_services/wound_care/wound_care_ center.aspx (last accessed January 9, 2017).

23. Conway Regional Health System Wound Healing Center. 2017. www.conwayregional.org/Wound Doctors (last accessed January 9, 2017).

24. The Wound Care Center at Rush Oak Park Hospital. 2015. www.roph.org/clinical-services/ wound-care (last accessed January 9, 2017).

25. Wilson Wound Healing Center. 2014. www .wilsonmedical.com/services/wilson-wound healing-center (last accessed January 9, 2017).

26. Wound Care Center at St. Catherine's Hospital. 2013. www.stcatherinehosp.org/sch/specialties/ wound-care-center (last accessed January 9, 2017).

27. St. Luke's Wound \& Hyperbaric Center. 2017. www.unitypoint.org/cedarrapids/services-woundhealing-center-cedar-rapids.aspx (last accessed January 9, 2017).

28. The Wound Care Center at Northern Nevada Medical Center. 2016. www.nnmc.com/hospitalservices/wound-care (last accessed January 9, 2017).

29. Wound Healing Center at Allegen General Hospital. 2017. www.aghosp.org/services/wound healing_center.aspx (last accessed January 9, 2017).

30. South County Health Wound Care Center. 2013. www.southcountyhealth.org/SouthCountyHospital NewsEvents/NiewArticle/tabid/164/Articleld/290/ OurServices/WoundCare/tabid/213/Default.aspx (last accessed March 6, 2017).

31. Leesburg Regional Medical Center Wound Care \& Hyperbaric Center. 2017. www.leesburg regional.org/services/wound-care (last accessed January 9, 2017).

32. Paul B. Hall Wound Healing Center. 2012. www .pbhrmc.com/Paul-B-Hall-Regional-Medical-Center/ medical-services/5247.aspx (last accessed January 9, 2017).

33. Baptist Easley Wound Care \& Hyperbaric Center. 2015. https://baptisteasley.org/hospital-services/ wound-care (last accessed January 9, 2017).

34. DCH Wound Healing Center. 2017. www.dchsystem .com/our_services/wound_healing_center.aspx (last accessed January 9, 2017).

35. The Wound Care Center at Providence Medical Group. 2017. http://montana.providence.org/ clinics/wound-care-center (last accessed January 9, 2017).

36. The Weirton Medical Wound Treatment Center 2017. www.weirtonmedical.com/programs-services/ wound-treatment-center.php (last accessed January 9, 2017).

37. Ridgeview Medical Center Wound \& Hyperbaric Healing Center. 2017. www.ridgeviewmedical .org/services/wound-care-hyperbaric-oxygentherapy (last accessed January 9, 2017)

38. Cascade Valley Hospital Wound Care \& Hyperbaric Medicine Center. 2014. www.cascadevalley .org/2014/17/cvhwchmc (last accessed January 9, 2017).

39. Brattleboro Memorial Hospital Center for Wound Healing. www.bmhvt.org/bmh-center-woundhealing-recognized-national-award-clinicalexcellence (last accessed January 9, 2017).

40. Southern Maine Health Care Wound \& Ostomy Care Center. www.smhc.org/care-and-services/ wound-and-ostomy-care-center (last accessed January 9, 2017).

41. Portneuf Wound Care and Hyperbaric Center 2016. www.eastidahonews.com/2016/04/portneufwound-care-center-receives-national-award-forexcellence-in-healing (last accessed January 9 , 2017).

42. Fauquier Health Wound Healing Center. www .fauquierhealth.org/wound-healing-center (last accessed January 9, 2017).

43. Johnson Memorial Hospital Wound Healing Center. 2017. www.johnsonmemorial.org/carecenters/general/wound-healing-center/769 (last accessed January 9, 2017).

44. Bayhealth Wound Care Center. www.bayhealth .org/wound-care (last accessed January 9, 2017).

45. Yavapai Regional Medical Center's Advanced Wound Care Center. 2016. www.yrmc.org/services/ advanced-wound-care/services (last accessed January 9, 2017).

46. Memorial Medical Center Wound Care Center. 2016. www.mmclc.org/services/wound-carecenter (last accessed January 9, 2017). 
47. Penrose-St. Francis Wound Care Clinic. 2017. www.penrosestfrancis.org/PSF/Specialties/WoundClinic/Wound-Clinic (last accessed January 9, 2017).

48. Center for Wound Care \& Hyperbaric Medicine at Comanche County Memorial Hospital. 2017. www.ccmhonline.com/wound-care (last accessed January 9, 2017)

49. St. Tammany Parish Hospital Clinic for Wound Care and Hyperbaric Medicine. 2015. www .stph.org/woundcare (last accessed January 9, 2017).

50. King's Daughters Wound Healing Center. 2017. http://kdmc.org/index.cfm/services/wound-care (last accessed January 9, 2017).

51. Mary Washington Healthcare Wound Healing Center. www.marywashingtonhealthcare.com/ Our-Services/Wound-Healing-Services.aspx (last accessed January 9, 2017).

52. Hardin HMC Wound Care Services. 2017. www .hardinmedicalcenter.org/facility_services/health_ services/wound_care_services.aspx (last accessed January 9, 2017).

53. Carter MJ, Fife CE, Walker D, Thomson B. Estimating the applicability of wound care randomized controlled trials to general wound-care populations by estimating the percentage of individuals excluded from a typical wound-care population in such trials. Adv Skin Wound Care 2009;22:316-324.

54. Serena TE, Fife CE, Eckert KA, Yaakov RA, Carter MJ. A new approach to clinical research: integrating clinical care, quality reporting, and research using a wound care network-based learning healthcare system. Wound Repair Regen 2017;25:354-365.

55. Watson JM, Kang'ombe AR, Soares M0, et al. VenUS III team. VenUS III: a randomised controlled trial of therapeutic ultrasound in the management of venous leg ulcers. Health Technol Assess 2011;15:1-192.

56. Ghatnekar GS, Grek CL, Armstrong DG, Desai SC, Gourdie RG. The effect of a connexin43-based peptide on the healing of chronic venous leg ulcers: a multicenter, randomized trial. J Invest Dermatol 2015;135:289-298.

57. Milio G, Minà C, Cospite V, Almasio PL, Novo S. Efficacy of the treatment with prostaglandin E-1 in venous ulcers of the lower limbs. J Vasc Surg 2005:42:304-308.

58. Michaels JA, Campbell WB, King BM, et al. A prospective randomised controlled trial and economic modelling of antimicrobial silver dressings versus non-adherent control dressings for venous leg ulcers: the VULCAN trial. Health Technol Assess 2009;13:1-114, iii.

59. Iglesias C, Nelson EA, Cullum NA, Torgerson DJ; VenUS Team. VenUS I: a randomised controlled trial of two types of bandage for treating venous leg ulcers. Health Technol Assess 2004;8:iii, 1105.

60. Mostow EN, Haraway GD, Dalsing M, Hodde JP, King D; OASIS Venus Ulcer Study Group. Effec- tiveness of an extracellular matrix graft (OASIS Wound Matrix) in the treatment of chronic leg ulcers: a randomized clinical trial. J Vasc Surg 2005;41:837-843.

61. Omar AA, Mavor Al, Jones AM, HomerVanniasinkam S. Treatment of venous leg ulcers with Dermagraft. Eur J Vasc Endovasc Surg 2004; 27:666-672.

62. Brizzio E, Amsler F, Lun B, Blättler W. Comparison of low-strength compression stockings with bandages for the treatment of recalcitrant venous ulcers. J Vasc Surg 2010;51:410-416.

63. Backhouse CM, Blair SD, Savage AP, Walton J, McCollum CN. Controlled trial of occlusive dressings in healing chronic venous ulcers. $\mathrm{Br} \mathrm{J}$ Surg 1987;74:626-627.

64. Davies CE, Woolfrey G, Hogg N, et al. Maggots as a wound debridement agent for chronic venous leg ulcers under graduated compression bandages: a randomised controlled trial. Phlebology 2015;30:693-699.

65. Harding K, Sumner M, Cardinal M. A prospective, multicentre, randomised controlled study of human fibroblast-derived dermal substitute (Dermagraft) in patients with venous leg ulcers. Int Wound J 2013;10:132-137.

66. Jull A, Walker N, Parag V, Molan P, Rodgers A; Honey as Adjuvant Leg Ulcer Therapy Trial Collaborators. Randomized clinical trial of honeyimpregnated dressings for venous leg ulcers. $\mathrm{Br}$ J Surg 2008:95:175-182.

67. Jünger $M$, Wollina U, Kohnen R, Rabe E. Efficacy and tolerability of an ulcer compression stocking for therapy of chronic venous ulcer compared with a below-knee compression bandage: results from a prospective, randomized, multicentre trial. Curr Med Res Opin 2004;20:1613-1623.

68. O'Halloran PD, Winter PK, Otter JA, Adams NM, Chewins $\mathrm{J}$. Aqueous oxygen peroxide treatment of VLUs in a primary care-based randomised, double-blind, placebo-controlled trial. J Wound Care 2014;23:176, 178, 180-181 passim.

69. Polignano R, Guarnera G, Bonadeo P. Evaluation of SurePress Comfort: a new compression system for the management of venous leg ulcers. $J$ Wound Care 2004;13:387-391.

70. Vanscheidt W, Harding K, Téot L, Siebert J. Effectiveness and tissue compatibility of a 12 week treatment of chronic venous leg ulcers with an octenidine based antiseptic-a randomized, double-blind controlled study. Int Wound J 2012;9:316-323.

71. Vin F, Teot L, Meaume S. The healing properties of Promogran in venous leg ulcers. J Wound Care 2002;11:335-341.

72. Weller CD, Evans SM, Staples MP, Aldons P, McNeil JJ. Randomized clinical trial of threelayer tubular bandaging system for venous leg ulcers. Wound Repair Regen 2012;20:822-829.

73. Brown $A$, Augustin $M$, Jünger $M$, et al. Randomized standard-of-care-controlled trial of a silica gel fibre matrix in the treatment of chronic ve- nous leg ulcers. Eur J Dermatol 2014;24:210216.

74. Robson MC, Phillips TJ, Falanga V, et al. Randomized trial of topically applied repifermin (recombinant human keratinocyte growth factor2) to accelerate wound healing in venous ulcers. Wound Repair Regen 2001;9:347-352.

75. Löndahl M, Katzman P, Nilsson A, Hammarlund C. Hyperbaric oxygen therapy facilitates healing of chronic foot ulcers in patients with diabetes. Diabetes Care 2010;33:998-1003.

76. Motley TA, Gilligan AM, Lange DL, Waycaster CR, Dickerson JE, Jr. Cost-effectiveness of clostridial collagenase ointment on wound closure in patients with diabetic foot ulcers: economic analysis of results from a multicenter, randomized, open-label trial. J Foot Ankle Res 2015;8:7.

77. Zykova SN, Balandina KA, Vorokhobina NV, Kuznetsova AV, Engstad R, Zykova TA. Macrophage stimulating agent soluble yeast $\beta-1,3 / 1,6$ glucan as a topical treatment of diabetic foot and leg ulcers: a randomized, double blind, placebo-controlled phase II study. J Diabetes Investig 2014;5:392-399.

78. Driver VR, Hanft J, Fylling $C P$, Beriou JM; Autologel Diabetic Foot Ulcer Study Group. A prospective, randomized, controlled trial of autologous platelet-rich plasma gel for the treatment of diabetic foot ulcers. Ostomy Wound Manage 2006;52:68-70, 72, 74 passim.

79. Edmonds M; European and Australian Apligraf Diabetic Foot Ulcer Study Group. Apligraf in the treatment of neuropathic diabetic foot ulcers. Int J Low Extrem Wounds 2009;8:11-18.

80. Gentzkow GD, Iwasaki SD, Hershon KS, et al. Use of Dermagraft, a cultured human dermis, to treat diabetic foot ulcers. Diabetes Care 1996; 19:350-354.

81. Hanft JR, Surprenant MS. Healing of chronic foot ulcers in diabetic patients treated with a human fibroblast-derived dermis. J Foot Ankle Surg 2002;41:291-299.

82. Lavery LA, Fulmer J, Shebetka KA, et al.; Grafix Diabetic Foot Ulcer Study Group. The efficacy and safety of Grafix( $\left({ }^{\circ}\right)$ for the treatment of chronic diabetic foot ulcers: results of a multicentre, controlled, randomised, blinded, clinical trial. Int Wound J 2014;11:554-560.

83. Marston WA, Hanft J, Norwood P, Pollak R; Dermagraft Diabetic Foot Ulcer Study Group. The efficacy and safety of Dermagraft in improving the healing of chronic diabetic foot ulcers: results of a prospective randomized trial. Diabetes Care 2003;26:1701-1705.

84. Piaggesi A, Macchiarini S, Rizzo L, et al. An offthe-shelf instant contact casting device for the management of diabetic foot ulcers: a randomized prospective trial versus traditional fiberglass cast. Diabetes Care 2007;30:586-590.

85. Zelen CM, Serena TE, Gould L, et al. Treatment of chronic diabetic lower extremity ulcers with 
advanced therapies: a prospective, randomised controlled, multi-centre comparative study examining clinical efficacy and cost. Int Wound $\mathrm{J}$ 2016;13:272-282.

86. Tsang MW, Wong WK, Hung CS, et al. Human epidermal growth factor enhances healing of diabetic foot ulcers. Diabetes Care 2003;26: 1856-1861.

87. Veves A, Falanga V, Armstrong DG, Sabolinski ML; Apligraf Diabetic Foot Ulcer Study. Graftskin, a human skin equivalent, is effective in the management of noninfected neuropathic diabetic foot ulcers: a prospective randomized multicenter clinical trial. Diabetes Care 2001;24: 290-295.

88. Veves A, Sheehan P, Pham HT. A randomized, controlled trial of Promogran (a collagen/oxidized regenerated cellulose dressing) vs standard treatment in the management of diabetic foot ulcers. Arch Surg 2002;137:822-827.

89. Driver VR, Lavery LA, Reyzelman AM, et al. A clinical trial of Integra Template for diabetic foot ulcer treatment. Wound Repair Regen 2015;23: 891-900.

90. Reyzelman A, Crews RT, Moore JC, et al. Clinical effectiveness of an acellular dermal regenerative tissue matrix compared to standard wound management in healing diabetic foot ulcers: a prospective, randomised, multicentre study. Int Wound J 2009;6:196-208.

91. Balingit PP, Armstrong DG, Reyzelman AM, et al NorLeu3-A(1-7) stimulation of diabetic foot ulcer healing: results of a randomized, parallel-group, double-blind, placebo-controlled phase 2 clinical trial. Wound Repair Regen 2012;20:482-490.

92. Li S, Zhao J, Liu J, Xiang F, et al. Prospective randomized controlled study of a Chinese herbal medicine compound Tangzu Yuyang Ointment for chronic diabetic foot ulcers: a preliminary report. J Ethnopharmacol 2011;133:543-550.

93. Li L, Chen D, Wang C, et al. Autologous plateletrich gel for treatment of diabetic chronic refractory cutaneous ulcers: a prospective, randomized clinical trial. Wound Repair Regen 2015;23:495505.

94. Rullan M, Cerdà L, Frontera G, Masmiquel L, Llobera J. Treatment of chronic diabetic foot ulcers with bemiparin: a randomized, triple-blind, placebo-controlled, clinical trial. Diabet Med 2008;25:1090-1095. Erratum in Diabet Med 2008; 25:1257.

95. Siavash M, Shokri S, Haghighi S, Shahtalebi MA, Farajzadehgan Z. The efficacy of topical royal jelly on healing of diabetic foot ulcers: a doubleblind placebo-controlled clinical trial. Int Wound J 2015;12:137-142.

96. Uccioli L, Giurato L, Ruotolo V, et al. Two-step autologous grafting using HYAFF scaffolds in treating difficult diabetic foot ulcers: results of a multicenter, randomized controlled clinical trial with long-term follow-up. Int $\mathrm{J}$ Low Extrem Wounds 2011;10:80-85.
97. You HJ, Han SK, Lee JW, Chang H. Treatment of diabetic foot ulcers using cultured allogeneic keratinocytes-a pilot study. Wound Repair Regen 2012;20:491-499.

98. You HJ, Han SK, Rhie JW. Randomised controlled clinical trial for autologous fibroblast-hyaluronic acid complex in treating diabetic foot ulcers. $\mathrm{J}$ Wound Care 2014;23:521-522, 524, 526-530.

99. Apelqvist J, Castenfors J, Larsson J, Stenström A, Persson G. Ketanserin in the treatment of diabetic foot ulcer with severe peripheral vascular disease. Int Angiol 1990;9:120-124.

100. Peters EJ, Lavery LA, Armstrong DG, Fleischli JG. Electric stimulation as an adjunct to heal diabetic foot ulcers: a randomized clinical trial. Arch Phys Med Rehabil 2001:82:721-725.

101. Kloth LC, Berman JE, Nett M, Papanek PE, DumitMinkel S. A randomized controlled clinical trial to evaluate the effects of noncontact normothermic wound therapy on chronic full-thickness pressure ulcers. Adv Skin Wound Care 2002:15:270-276.

102. Thomas DR, Diebold MR, Eggemeyer LM. A controlled, randomized, comparative study of a radiant heat bandage on the healing of stage 34 pressure ulcers: a pilot study. J Am Med Dir Assoc 2005;6:46-49.

103. Fife CE, Eckert KA. Harnessing electronic healthcare data for wound care research: standards for reporting observational data obtained directly from electronic health records. Wound Repair Regen 2017;25:192-209.

104. Fife CE, Carter MJ. Wound care outcomes and associated cost among patients treated in US outpatient wound centers: data from the US Wound Registry. Wounds 2012;24:10-17.

105. Carter MJ. Harnessing electronic healthcare data for wound care research: wound registry analytic guidelines for less-biased analyses. Wound Repair Regen 2017 [Epub ahead of print] DOI: 10.1111/wrr.12565

106. Ennis WJ, Fiberger E, Messner K, Meneses P. Wound healing outcomes: the impact of site of care and patient stratification. Wounds 2007;19: 286-293.

107. Gottrup F, Apelqvist J, Price P; European Wound Management Association Patient Outcome Group. Outcomes in controlled and comparative studies on non-healing wounds: recommendations to improve the quality of evidence in wound management. J Wound Care 2010;19: 237-268.

108. U.S. Food and Drug Administration. Guidance for industry chronic cutaneous ulcer and burn wounds-developing products for treatment. August 29, 2016. www.fda.gov/downloads/drugs/ guidancecomplianceregulatoryinformation/ guidances/ucm071324.pdf. (last accessed March 15, 2017).

109. Healogics. 2017. http://healogics.com (last accessed March 23, 2017).

110. Healogics. 2015-Center-of-Excellence-Award-PressRelease-FINAL. https://view.officeapps.live.com/
op/view.aspx?src=http\%3A\%2F\%2Fwww.healogics .com\%2FHome\%2Flanding-Pages\%2F2015-Centerof-Excellence-Award-press-release-FINA.doc (last accessed March 23, 2017).

111. Margolis DJ, Gross EA, Wood CR, Lazarus GS Planimetric rate of healing in venous ulcers of the leg treated with pressure bandage and hydrocolloid dressing. J Am Acad Dermatol 1993; 28:418-421.

112. Santema TB, Poyck PP, Ubbink DT. Systematic review and meta-analysis of skin substitutes in the treatment of diabetic foot ulcers: highlights of a Cochrane systematic review. Wound Repair Regen 2016;24:737-744.

113. Ennis WJ, Lee C, Vargas M, Meneses P. Wound outcomes from a single practice at a sub-acute wound care unit and two hospital-based, outpatient wound clinics. Wounds. 2004;16:164-172.

114. National Quality Forum (NQF). Guidance for measure harmonization: a consensus report Washington, DC: NQF, 2010. www.qualityforum .org/Publications/2011/05/Guidance_for_Measure_ Harmonization.aspx (last accessed August 15, 2017).

115. Fife CE. The truth about "wound healing rates." Today's Wound Clinic. May 19, 2015; www.to dayswoundclinic.com/blog/truth-about-woundhealing-rates (last accessed September 14, 2017).

116. Fife CE, Carter MJ, Walker D. Why is it so hard to do the right thing in wound care? Wound Repair Regen 2010;18:154-158.

117. Centers for Medicare and Medicaid Services Benchmarks for measures included in the performance year 2016 quality and resource use reports. 2017. www.cms.gov/Medicare/MedicareFee-for-Service-Payment/PhysicianFeedback Program/Downloads/PY2016-Prior-Year-Benchmarks .pdf (last accessed April 27, 2017).

118. Centers for Medicare \& Medicaid Services. Quality payment program. https://qpp.cms.gov (last accessed March 15, 2017).

119. Driver VR, Gould LJ, Dotson P, Gibbons GW, Li WW, Ennis WJ, et al. Identification and content validation of wound therapy clinical endpoints relevant to clinical practice and patient values for FDA approval. Part 1. Survey of the wound care community. Wound Repair Regen 2017;25 454-465.

\section{Abbreviations and Acronyms}

CMS $=$ The Centers for Medicare and Medicaid Services

DFU = diabetic foot ulcer

FDA $=$ Food and Drug Administration

MIPS = Merit-based Incentive Payment System

PQRS $=$ Physician Quality Reporting System

$\mathrm{PU}=$ pressure ulcer

OCDR $=$ Qualified Clinical Data Registry

$\mathrm{RCT}=$ randomized controlled trial

$\mathrm{SD}=$ standard deviation

UHM $=$ Undersea and Hyperbaric Medicine

USWR $=$ U.S. Wound Registry

$\mathrm{VLU}=$ venous leg ulcer 